LA GRANJA:
REVISTA DE
CIENCIAS DE LA VIDA
pISSN:1390-3799; eISSN:1390-8596
http://doi.org/10.17163/lgr.n32.2020.10

\title{
CORONAVIRUS EN ECUADOR: UNA OPINIÓN DESDE LA ACADEMIA
}

\author{
CORONAVIRUS IN ECUADOR: AN OPINION FROM THE ACADEMIA
}

Santiago Guerrero®

\author{
Centro de Investigación Genética y Genómica. Facultad de Ciencias de la Salud Eugenio Espejo, Universidad UTE. Av. Mariscal \\ Sucre y Av. Mariana de Jesús, Bloque I, 2do piso, 170129 Quito, Ecuador \\ *Autor para correspondencia: sxguerrero@gmail.com
}

\begin{abstract}
Resumen
Esta es la tercera vez que un coronavirus zoonótico ha podido infectar diversas poblaciones humanas. Este nuevo virus, clasificado como SARS-CoV-2 (severe acute respiratory syndrome coronavirus 2), es el agente causal de la epidemia denominada COVID-19 (coronavirus disease 2019). La investigación internacional realizada en torno a este nuevo brote fue tan eficaz que en poco tiempo ya se conocía el genoma del virus, su biología y sus principales aspectos epidemiológicos. En Ecuador se han reportado hasta la fecha 1962 casos positivos de SARS-CoV-2, situación que generó una gran preocupación por parte de la sociedad y la Academia ecuatoriana. Por lo tanto, en este artículo de opinión se detallarán las principales investigaciones realizadas sobre el SARS-CoV-2 a nivel internacional, se discutirá sobre la importancia de la Academia en la toma de decisiones sanitarias y se pondrá en perspectiva el papel de la investigación fundamental para la contención de un posible brote en Ecuador.
\end{abstract}

Palabras clave: coronavirus, SARS-CoV-2, COVID-19, Ecuador.

\begin{abstract}
This is the third time that a zoonotic coronavirus has infected various human populations. This new virus, classified as SARS-CoV-2 (severe acute respiratory syndrome coronavirus 2), is the causative agent of the new pandemic outbreak called COVID-19 (coronavirus disease 2019). The international research carried out around this new outbreak was so effective that shortly thereafter the genome of the virus, its biology and its main epidemiological aspects were determined. To date, 1962 positive cases of SARS-CoV-2 have been reported in Ecuador, situation that has caused great concern among Ecuadorian academics and society. Thus, in this opinion article, the main research carried out internationally on the SARS-CoV-2 will be detailed, the importance of the Academia in healthcare decision-making will be discussed and the role of fundamental research to hold a possible outbreak in Ecuador will be mentioned.
\end{abstract}

Keywords: coronavirus, SARS-CoV-2, COVID-19, Ecuador. 
Forma sugerida de citar: Guerrero, S. (2020). Coronavirus en Ecuador: una opinión desde la Academia. La Granja: Revista de Ciencias de la Vida. Vol. 32(2):127-133. http:/ / doi.org/10.17163/lgr.n32. 2020.10 .

ID Orcid:

Santiago Guerrero: http:/ / orcid.org/0000-0003-3473-7214 


\section{Introducción}

"Otra década, otro coronavirus" se titula el editorial publicado por Stanley Perlman en la prestigiosa revista The New England Journal of Medicine. Efectivamente, esta es la tercera vez que un coronavirus zoonótico ha podido infectar diversas poblaciones humanas. Al igual que el SARS-CoV (severe acute respiratory syndrome coronavirus) en 2002-2003 y el MERS-CoV (Middle East respiratory syndrome coronavirus) en 2012, este nuevo virus, denominado SARSCoV-2 (severe acute respiratory syndrome coronavirus 2), también se transmitió de animales a humanos (Perlman, 2020).

Los coronavirus pueden causar infecciones virales del tracto respiratorio superior (IVTRS) en una gran variedad de animales domésticos y salvajes, así como también en humanos. Estos virus no se consideraban altamente patógenos para los humanos hasta que ocurrió el brote de SARS-CoV en la provincia de Guangdong, China. Los coronavirus que circulaban antes de este brote sólo causaban infecciones leves en personas inmunodeprimidas. Diez años después del SARS-CoV, otro coronavirus zoonótico altamente patógeno (MERS-CoV) surgió en los países del Medio Oriente. Este último se transmitió directamente de camellos a humanos, mientras que el SARS-CoV de civetas vendidas en mercados; ambos virus se cree que se originaron en murciélagos (Perlman, 2020).

En la actualidad existen más de 200 tipos virales serológicamente diferentes que causan IVTRS. La sintomatología de las IVTRS depende de la naturaleza del virus, pero en mayor medida está modulada por la edad, el estado fisiológico y la respuesta inmune del hospedero. De esta forma, dependiendo de estos factores, las IVTRS pueden pasar desapercibidas (asintomáticas) hasta causar la muerte. Los principales agentes causantes de IVTRS en humanos son los rinovirus $(30-50 \%$ de casos), seguido por los coronavirus $(10-15 \%)$, los virus de la influenza $(5-10 \%)$ y otros virus de menor incidencia como los adenovirus, el virus sincitial respiratorio humano, entre otros (Eccles, 2005).

La gran diversidad viral dificulta la detección causante de IVTRS y el desarrollo de métodos de diagnóstico al momento de un nuevo brote. Por ejemplo, el brote de SARS-CoV apareció en no- viembre de 2002 pero no fue hasta abril de 2003 que se identificó el genoma del virus gracias a una colaboración internacional de 13 laboratorios pertenecientes a 10 países (Cui, Li y Shi, 2019). Una vez determinado el genoma del virus se utiliza la reacción en cadena de la polimerasa con transcriptasa inversa en tiempo real (real time RT-PCR, del inglés reverse transcription polymerase chain reaction) para amplificar una región especifica del virus e identificarlo a nivel molecular.

La identificación molecular del virus y el estudio de su biología y epidemiología es de gran importancia para la contención de un brote epidémico, desarrollo de medicamentos y políticas de salud pública encaminadas a evitar la diseminación de este tipo de virus. Por lo tanto, en este artículo de opinión se detallarán las principales investigaciones realizadas sobre el SARS-CoV-2 a nivel internacional, se discutirá sobre la importancia de la Academia en la toma de decisiones sanitarias y se podrá en perspectiva el papel de la investigación fundamental para la contención de un posible brote en Ecuador.

\section{SARS-CoV-2: identificación, epi- demiología y tratamiento}

El SARS-CoV-2 es el agente causal de la nueva epidemia denominada COVID-19 (coronavirus disease 2019) que se originó en Wuhan, China. Los primeros casos fueron reportados a finales de diciembre de 2019 por las autoridades chinas a la Organización Mundial de la Salud (OMS). La investigación para determinar el agente causal del COVID-19 fue tan exhaustiva que, para el 7 de enero de 2020, científicos del Centro Clínico de Salud Pública de Shanghai, asociado a la Universidad de Fudan, identificaron el patógeno responsable del COVID-19 y lo caracterizaron genómicamente (Liu, Bing y Za Zhi, 2020).

La secuencia genética del SARS-CoV-2, compartida al público mediante la iniciativa GISAID (Global Initiative on Sharing All Influenza Data), permitió el desarrollo rápido de pruebas de diagnóstico mediante la técnica de real time RT-PCR a nivel mundial. De esta forma, para el 17 de enero de 2020, científicos de la Universidad Charité de Berlín compartieron el protocolo de detección a la OMS y pusieron a disposición mundial los controles po- 
sitivos mediante el EVAg (European Virus Archive global). Posteriormente, científicos de Hong Kong, Japón, China, Tailandia y Estados Unidos, asociados a universidades e institutos públicos compartieron sus protocolos de detección a la OMS entre el 23 y 28 de enero de 2020 (Corman y col., 2020a). Actualmente, 133 secuencias parciales o completas del virus están ya disponibles en el GenBank. (https://www.ncbi.nlm.nih.gov/genbank/).

A nivel clínico epidemiológico, el mayor estudio publicado hasta la fecha, realizado por el China CDC (Chinese Center for Disease Control and Prevention), analizó 72314 registros de pacientes: 44,672 (61,8\%) casos confirmados, 16186 $(22,4 \%)$ casos sospechosos, $10567(14,6 \%)$ casos diagnosticados clínicamente y 889 casos asintomáticos $(1,2 \%)$. Entre los casos confirmados, $1023 \mathrm{mu}-$ rieron dando como resultado una tasa de mortalidad de $2,3 \%$. A pesar de que la tasa de mortalidad es baja, esta aumenta a $8 \%$ en individuos de 70-79 años y a $14 \%$ en pacientes mayores a 80 años; estos pacientes también presentaron condiciones preexistentes, tales como hipertensión, enfermedades cardiovasculares y diabetes. Además, este estudio determinó que el $80,9 \%$ de las infecciones se clasifican como leves, el 13,8\% como graves y solamente el 4,7\% como críticas. Con respecto a los brotes anteriores, el SARS-CoV infectó a 8096 individuos en 29 países, causando la muerte a 774 personas (tasa de mortalidad: 9,6\%), mientras que el MERS-CoV infectó a 2494 personas en 27 países, causando 858 víctimas (tasa de mortalidad: 34,4\%) (Huang y col., 2020; Liu, Bing y Za Zhi, 2020).

Actualmente varios institutos y centros de investigación, junto a empresas biotecnológicas, se encuentran desarrollando posibles vacunas contra el SARS-CoV-2. La investigación en este campo también avanzó a pasos agigantados. A tan solo semanas después de la publicación del genoma del SARS-CoV-2, científicos asociados al Instituto Nacional de Alergias y Enfermedades Infecciosas (E.E.U.U.) y a la Universidad de Texas lograron resolver la estructura de la glicoproteína $S$ de este virus. Esta proteína está implicada en la entrada del virus a las células hospederas y su estructura es clave para el desarrollo de vacunas, anticuerpos terapéuticos y métodos de diagnóstico (Wrapp y col., 2020).
Otra estrategia para combatir el virus es utilizar antivirales desarrollados para tratar otras infecciones. En este sentido, el hospital Jinyintan de Wuhan está llevando a cabo un ensayo controlado aleatorizado para tratar pacientes diagnosticados con COVID-19. Este ensayo tiene como objetivo probar la eficacia de una combinación de lopinavir y ritonavir, medicamentos ya usados para tratar el VIH (Huang y col., 2020). Estos compuestos inhiben la proteasa, una enzima utilizada tanto por el VIH como por los coronavirus para el procesamiento de nuevas partículas virales. Previamente, en 2004, un estudio demostró que dicha combinación puede tener un efecto clínico positivo en pacientes infectados con una cepa similar al SARS-CoV-2. Sin embargo, el estudio no aleatorizó a los pacientes para recibir la combinación o un placebo, lo cual es prioritario para un ensayo controlado. Además, otros dos ensayos están en curso para probar la eficacia del remdesivir en 760 personas con COVID-19 en China. Este compuesto mostró una gran eficacia contra varios coronavirus in vitro e in vivo, incluyendo el SARS-CoV y el MERS-CoV (Cohen, 2020). Actualmente, China tiene más de 80 ensayos clínicos en ejecución o pendientes sobre posibles tratamientos para el COVID-19 (Maxmen, 2020).

\section{Situación en Ecuador}

Hasta la fecha (30-mar-2020) se han reportado 1962 casos positivos de SARS-CoV-2 y 62 muertes en Ecuador. Durante los primeros días de la epidemia, el 26 de enero de 2020, el Ministerio de Salud Pública del Ecuador (MSP) anunció la presencia de un caso sospechoso de COVID-19. Se trataba de un ciudadano chino de 49 años de edad que presentaba la sintomatología asociada a esta enfermedad: temperatura elevada $\left(39^{\circ} \mathrm{C}\right)$, tos con flema verdosa, dolor torácico y signos de insuficiencia renal y respiratoria grave (Figura 1) (MSP, Ministerio de Salud Pública del Ecuador, 2020).

Para diagnosticar el caso, el MSP envió las muestras para su análisis a los Centros para el Control y la Prevención de Enfermedades (CDC, del inglés Centers for Disease Control and Prevention) ubicado en Atlanta (E.E.U.U). Según comunicados oficiales emitidos el 29 de enero y el 1 de febrero de 2020, Ecuador todavía no recibía los resultados del CDC; sin embargo, no fue hasta el 4 de febrero que el MSP 
descartó la presencia de SARS-CoV-2 en base a los resultados presentados por el CDC. Finalmente, el ciudadano chino en cuestión falleció el 7 de febrero presentando un cuadro de hepatitis B y neumonía (Figura 1) (MSP, Ministerio de Salud Pública del Ecuador, 2020). Durante la espera de los resultados por parte del CDC, el MSP también anunció que el Instituto Nacional de Investigación en Salud Pública (INSPI) cuenta con los reactivos necesarios para la identificación de futuros casos sospechosos (Figura 1). Este instituto cuenta con el Centro de Referencia Nacional de Influenza y otros Virus Respiratorios, una organización acreditada por la OMS para la realización de pruebas que permitan diagnosticar posibles casos de SARS-CoV-2 (MSP,
Ministerio de Salud Pública del Ecuador, 2020).

Semanas después, el 29 de febrero de 2020, el MSP reportó el primer caso de COVID-19 (Figura 1). Se trataba de una ciudadana ecuatoriana residente en España que ingresó al país el 14 de febrero por el aeropuerto José Joaquín de Olmedo. Posteriormente, de los 177 ciudadanos que estaban en el cerco epidemiológico respecto al primer caso, 1962 han dado positivo para SARS-CoV-2 (MSP, Ministerio de Salud Pública del Ecuador, 2020). Cabe recalcar que el diagnostico se dió 5 días después del ingreso al hospital y 13 días después de su llegada al Ecuador (MSP, Ministerio de Salud Pública del Ecuador, 2020).

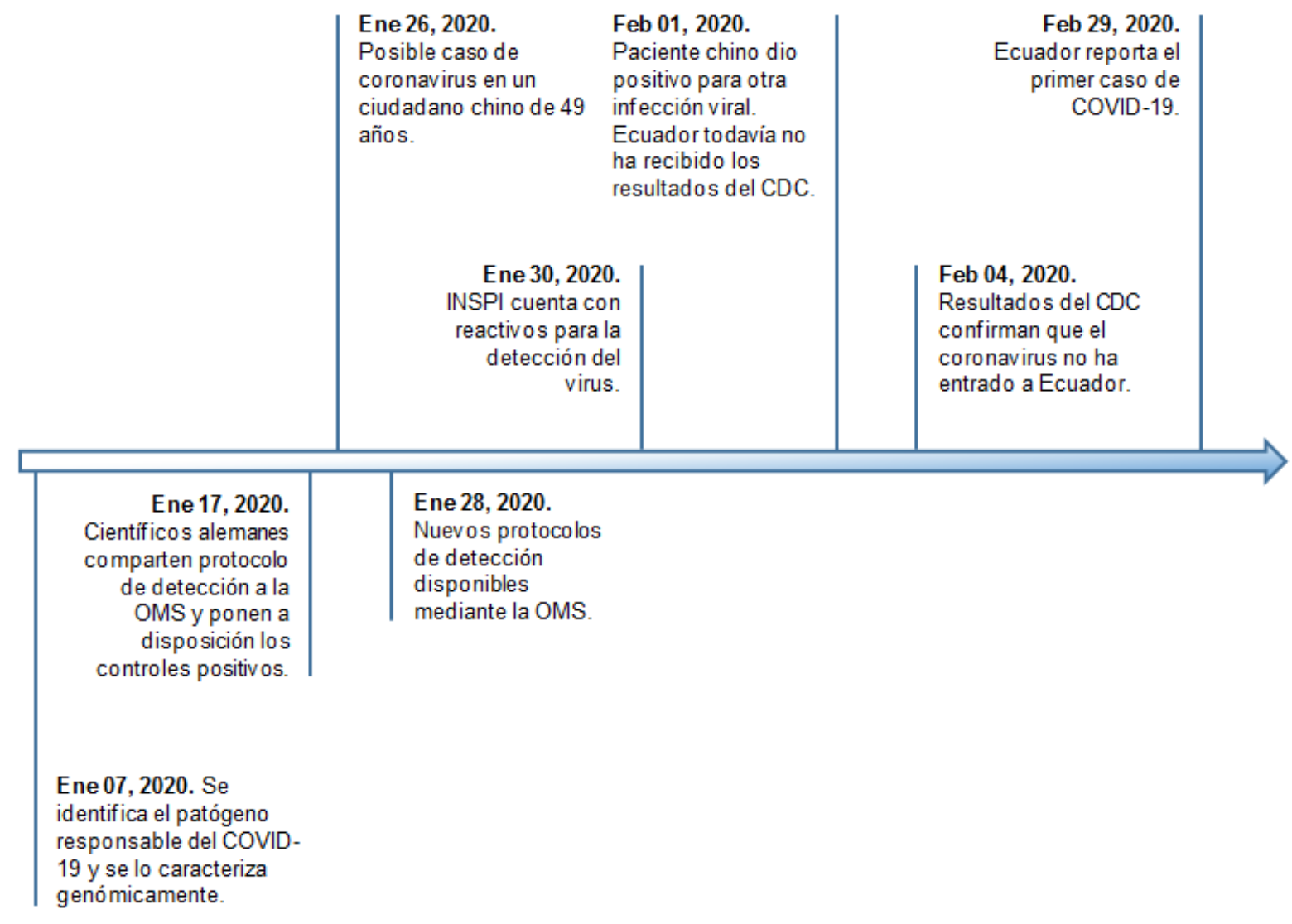

Figura 1. Principales eventos ocurridos en Ecuador y a nivel internacional sobre la detección del SARS-CoV-2 en los primeros días de la epidemia. 


\section{Perspectivas para el Ecuador}

La investigación internacional realizada en torno a este nuevo brote fue tan eficaz que en tan solo meses se descubrió el agente causal del COVID-19, su biología - destacando su genoma y la estructura de la glicoproteína S- y su epidemiología. La investigación avanzó a tal punto que existen 80 ensayos clínicos en ejecución o pendientes sobre posibles tratamientos para esta enfermedad. Además, varios institutos y centros de investigación, en colaboración con la industria, se encuentran desarrollando posibles vacunas. Esto se ha logrado en gran medida por una estrecha colaboración entre grupos de investigación universitarios, centros de investigación públicos y empresas biotecnológicas.

En Ecuador es indispensable que la Academia, por medio de sus instituciones acreditadas, e.g. Academia de Ciencias del Ecuador (AEC) o grupos de investigación consolidados, colabore estrechamente con el Estado para generar investigación fundamental y aplicada en temas de importancia nacional. De esta forma, Ecuador podría generar una respuesta más eficaz para la contención de la pandemia. Esto está respaldado por las recomendaciones de la OMS con respecto a la formación de Centros de Operaciones de Emergencia (COE) para la toma de decisiones sanitarias. Los COE, conformados por varias entidades incluyendo la Academia, gestionan la respuesta a una gran variedad de peligros, tales como desastres naturales, derrames químicos, brotes epidémicos, etc (Balajee y col., 2017).

Contrariamente al resto de países, Ecuador no ha publicado ningún reporte científico sobre los casos positivos de SARS-CoV-2 que circulan en el país. Para generar una respuesta sanitaria eficaz, es indispensable que el MSP publique los casos clínicos de COVID-19 en revistas especializadas. Los reportes de casos clínicos presentan la evidencia más baja dentro de la escala de la investigación científica y se consideran como la primera fuente de información a nivel médico (Pineda-Leguízamo, Miranda-Novales y Villasis-Keever, 2018). En base a dichos reportes, los médicos de atención primaria podrán evaluar de mejor manera futuros casos sospechosos en Ecuador. Asimismo, la identificación genética de las cepas de SARS-CoV-2 presentes en Ecuador ayudará a implementar de manera más eficaz los protocolos de contención, debido a que el virus evolucionó hacia dos tipos: L y S, denominadas en base a sus variantes genéticas. El tipo L es más agresiva y se transmite más rápido que la $S$ (Tang y col., 2020). En Ecuador se desconoce todavía qué cepa infectó a los pacientes diagnosticados con COVID-19. A nivel internacional, este tipo de investigaciones se han realizado gracias a una estrecha colaboración entre la Academia y el Estado.

Por otro lado, Ecuador alberga un sorprendente número de especies endémicas que habitan en una gran variedad de ecosistemas. Con respecto a los murciélagos, principal reservorio de los coronavirus, el museo de Zoología de la Pontificia Universidad Católica del Ecuador ha registrado 176 especies de murciélagos en el país (Brito y col., 2019). Un estudio publicado en 2013, liderado por Christian Drosten, quien publicó el protocolo alemán de detección de SARS-CoV-2 (Corman y col., 2020b), encontró una gran diversidad de coronavirus en murciélagos neotropicales muestreados en Costa Rica, Panamá, Ecuador y Brasil. Sin embargo, de 1.868 muestras colectadas, solamente 62 (26 especies representadas) fueron obtenidas en Ecuador y ninguna muestra resultó positiva para coronavirus (Corman y col., 2013). Esto pone en evidencia la necesidad de estudiar la diversidad de coronavirus en Ecuador para determinar las zonas geográficas que puedan tener un alto riesgo de brotes zoonóticos. En efecto, la forma más efectiva de prevenir estos brotes es identificar dichas zonas y mantener las barreras entre los reservorios naturales y la civilización.

Para realizar este tipo de investigaciones, Ecuador necesita una diversificación de grupos de investigación que desarrollen líneas de estudio específicas, tales como los coronavirus u otro tipo de virus zoonóticos. Sin embargo, según datos del Banco Mundial https://www.bancomundial.org/, Ecuador destina tan sólo 0,44\% del Producto Interno Bruto (PIB) en investigación. Otros países de América Latina, tales como Argentina y Brasil destinan $0,53 \%$ y $1,2 \%$, respectivamente. La diferencia es abismal con países más desarrollados: China, $2,11 \%$ y EE.UU., $2,7 \%$. Con un financiamiento adecuado y enfocado a las prioridades de investigación del país, Ecuador no solamente podrá afrontar cualquier brote zoonotico sino también ser partícipe de la investigación internacional. 


\section{Referencias}

Balajee, S. y col. (2017). «Sustainable Model for Public Health Emergency Operations Centers for Global Settings.» En: Emerging Infectious Diseases 23.13, Online: https: / / bit.ly/2WRMOlI.

Brito, J. y col. (2019). Mamíferos del Ecuador. Versión 2019.0.

Cohen, J. (2020). Can an anti-HIV combination or other existing drugs outwit the new coronavirus?

Corman, V. y col. (2013). «Highly diversified coronaviruses in neotropical bats». En: The Journal of general virology 94, 1984-1994. Online:https: / / bit.ly/2G4dU2X.

Corman, V. y col. (2020a). «Detection of 2019 novel coronavirus (2019-nCoV) by real-time RT-PCR». En: Euro surveillance : bulletin Europeen sur les maladies transmissibles $=$ European communicable disease bulletin 25.3, 2000045. Online:https: / / bit. ly/39gJH9z.

Corman, V. y col. (2020b). Diagnostic detection of 2019-nCoV by real-time RT-PCR. Rep. de inv. 2. Berlin, Germany: Charité Virology.

Cui, J., F. Li y Z. L. Shi (2019). «Origin and evolution of pathogenic coronaviruses». En: Nature Reviews Microbiology. Nature Publishing Group 17.3, 181-192. Online:https:/ / bit.ly/3aniJOW.

Eccles, R. (2005). «Understanding the symptoms of the common cold and influenza». En: Lancet Infectious Diseases 5.11, 718-25. Online: https:/ / bit. ly/2Uiilf8.

Huang, C. y col. (2020). «Clinical features of patients infected with 2019 novel coronavirus in Wuhan,
China». En: The Lancet 395.10223, 497-506. Online: https:/ /bit.ly /2y8T0eV.

Liu, Zhonghua, Xing Bing y Xue Za Zhi (2020). «The epidemiological characteristics of an outbreak of 2019 novel coronavirus diseases (COVID-19) in China». En: Lancet 41.2, 145-151. Online:https:/ / doi.org/10.3760/cma.j.issn.0254 \bibrangedash 6450.2020.02.003.

MSP, Ministerio de Salud Pública del Ecuador (2020). «Comunicados oficales del Ministerio de Salud Pública del Ecuador». En: ed. por https:/ / www.salud.gob.ec/category/comunicamos/.

Maxmen, A. (2020). «More than 80 clinical trials launch to test coronavirus treatments». En: $\mathrm{Na}$ ture 578.7795, 347-348. Online:https: / / bit.ly / 3braEsM.

Perlman, S. (2020). «Editorial: Another Decade, Another Coronavirus». En: New England Journal of Medicine, 1-2: Online:https : / / doi . org / 10. 1056/nejme2001126.

Pineda-Leguízamo, R., G. Miranda-Novales y M. Á. Villasis-Keever (2018). «La importancia de los reportes de casos clínicos en la investigación». En: Revista Alergia México 65.1, 92. Online:https: //doi.org/10.29262/ram.v65i1.348.

Tang, Xiaolu y col. (mar. de 2020). "On the origin and continuing evolution of SARS-CoV-2». En: National Science Review.

Wrapp, D. y col. (2020). «Cryo-EM structure of the 2019-nCoV spike in the prefusion conformation». En: Science 367.6483, 1260-1263. Online:https://bit.ly/2Ju8f4N. 